\title{
External Integration Network and Competitive Advantage of China Creative Firms:Comicfans's Case Study
}

\author{
Shenglei $\mathrm{Pi}^{1}$, Danyi Qiu², $\mathrm{Li} \mathrm{Cao}^{3}$ \\ ${ }^{1}$ Industrial Economics Institute of Business and Management ,Guangzhou Academy of Social \\ Sciences, Guangzhou 510410, China; \\ ${ }^{2}$ Department of Business Administration, Nanfang College of Sun Yat-Sen University, Guangzhou \\ 510970, China; \\ ${ }^{3}$ Guagnzhou PATES Business Consultant Company, Guangzhou 510410, China
}

Keywords: creative firms external integration networks competitive behavior Comicfans

\begin{abstract}
Integration strategy is an important strategic behavior of firms. The study took Guangzhou Comicfans as an example, which mainly focused on the analysis of the competitive behavior, network integration features and firm network performance, etc..With information collected, we found that: Comicfans culture and other creative firms integrate external objects contained innovation agencies and resources, industry affiliates and social resources, including government departments, which formed from the content of cooperation, to teamwork, to co-products, to extend a series of integrated products cooperation. The contribution of the study was: (1) Supplemented with external integration creative firms had network characteristics; (2) External integration networks of creative firms had some evolutionary paths; (3) Firm integration behavior and competitive behavior need to be coordinated to create competitive advantage in the integration network of creative enterprises.
\end{abstract}

\section{Introduction}

Integration strategy was an important strategic behavior of firms, and scholars studied it from many perspectives. They discussed the way of the integration, including the acquisition [1], the union [2] and so on. Some of them paid attention to the influence of differences of government and institution in the whole process of integration. Yip $(1988,1989)$ had put forward the $[3,4]$ globalized management mode. Since then, scholars discussed the centralization(Ali Haj \& William, 2004)[5] ,transaction costs [6], commissioned agent theory [7] perspectives, trying to find the an intervention system which could develop a synergistic effect of the organization mode, including governance structure and organizational structure [8] and so on. Most of the prior researches were based on multinational firms, especially researching the manufacturing industry as the object of study. However , the creative firms were often light assets, leading to the creative firms integration strategy choose the form of alliances, which was bound to form a group alliance, or integrating network (Bartlett \& Ghoshal, 1989)[9] in the development process of creative firms. So for the creative firms, the following problems were also very important: (1) The integration strategy of creative firms faced a variety of different industries and fields, including government agencies, whether and how to design an integrated path easier to establish competitive advantages? (2) In the process of the construction and evolution of the network of creative firm alliance, what kind of competitive behavior should be taken to effectively play the benefit of resource integration, and how to build a better advantage? (3) In the process of establishing a creative firm integration network, what kind of role did it play in the relationship between the government and the government? These three issues were important to the market system of creative firms and other emerging markets in the creative firms. This study choose Chinese Comicfans to try to answer these three questions.

\section{Case Study Design}

We had chosen a famous firm-Comicfans an example. Guangzhou Comicfans Culture Technology Co.,Ltd. ,established in 1997, was one of the biggest animation contents and service providers in China. It had mainly engaged in the planning and distribution of comic books and 
journals, the creation and the operation of comic contents, and was a national key animation firm and national cultural industry demonstration base.

\section{1 variable design}

(1)Competitive behavior. Considering the particularity of the cultural industry, this study would be based on previous and was divided into eight categories: investment or acquisition, alliance or cooperation, development of new technologies, new products, starting new stores or new regional markets, changing in organizational structure or marketing network, the changing price, and carrying out public the relationship between activities.

(2)Frequency of competitive behavior. Above eight kinds of competitive behavior in the development of new technologies, new products, opening new stores or new regional markets, four kinds of changes in the market price of the behavior, the total frequency for each year of the four actions of the business to become the market frequency. At the same time, the frequency of each behavior according to the specific scope of behavior was divided into national frequency of behavior and regional frequency of behavior.

(3)Competitive complexity. Complexity of competitive strategy combination refered to the action of firms to implement differentiated range (Ferrier et al, 1999;. Nayyar \& Bantel, 1994)[10] as well as the field of competitive behavior ( Gnyawali et al, 2006) [11]. The book followed the (Ferrier) et al. (1999) and estimated that the simplicity of competitive behavior algorithm, seeking simplicity of reciprocal complexity:

Com $=1 / \sum_{a}\left(N_{a} / N T_{L}\right)^{2}$

$N_{a}$ represented the frequency of a year of a firm's a kind of competitive behavior, and $N T_{L}$ represented the total number of competitive behavior of the year. At the same time, Comicfans existed the complexity of the national behavior and regional behavior.

(4)Network density. In this study, Network density refered to the construction of comicfans integrated network process, associating with various government departments, firms and associations.

(5)Government level.Scoring for the association with Comicfans and government departments (national=3, provincial $=2$, municipal and below $=1$, non government $=0$ ), after figuring out the average value of the political hierarchy of all the integrated actions, we got the government level.

(6)Government relationship. Government relationship levels of Comicfans divided by the whole year all the consolidation behavior.

\subsection{Chain of evidence case}

Based on the basic method of case studies, we gathered Comicfans from 1997 to 2013 the relevant information through different channels. Data collected included four ways: interviewing with corporate executives, collecting information on Comicfans' news by "Infobank News and Information Platform” (http://www.infobank.cn/), and organizing documents relating to the strategy assessment. Four kinds of specific information on the data shown in chart 1 . The study focused on the analysis of the competitive behavior of firms, the integrated network and firm network performance and other characteristics of the collected information may reflect the situation of these firms from two to three different angles.

Chart 1 Comicfans case study evidence chain

\begin{tabular}{|l|l|l|l|l|}
\hline Data collection methods & Collected objects & Data form & Quantity & Variable \\
\hline $\begin{array}{l}\text { Interviews with senior } \\
\text { executives }\end{array}$ & $\begin{array}{l}\text { Xianfeng } \\
\text { Zhang,ect. }\end{array}$ & Recording & & Competitive behavior \\
\hline News report & Infobank & Text & 44 & $\begin{array}{l}\text { Competition, network } \\
\text { integration }\end{array}$ \\
\hline $\begin{array}{l}\text { Related documents } \\
\text { Enterprise Strategy } \\
\text { Assessment }\end{array}$ & $\begin{array}{l}\text { Comicfans } \\
\text { enterprise }\end{array}$ & Electronic text & $6.23 \mathrm{M}$ & Network Integration \\
\hline $\begin{array}{l}\text { Enterprise Development } \\
\text { Events }\end{array}$ & $\begin{array}{l}\text { Comicfans official } \\
\text { website }\end{array}$ & Text and data & 315 & $\begin{array}{l}\text { Competitive behavior, } \\
\text { network integration, } \\
\text { enterprise performance }\end{array}$ \\
\hline
\end{tabular}

\section{Construction and Its Implications of Comicfans external integration network}

\subsection{Guangzhou Comicfans integration of network evolution}

In comicfans as the core of the integrated network evolution and development of the various stages of the arrangement in Figure 1. At first, Comicfans established relationship with government 
departments. And then, it focused on strengthening in government departments and industry associations and society contact. Finally, it returned to the industrial chain, strengthening the upstream and downstream (especially the downstream) alliance and cooperative firms.The results showed that in the process of integrating external resources, Comicfans formed a series of integration from the content of cooperation, teamwork, cooperation and extended product cooperation.

Figure 1: Integrated network diagram of Comicfans
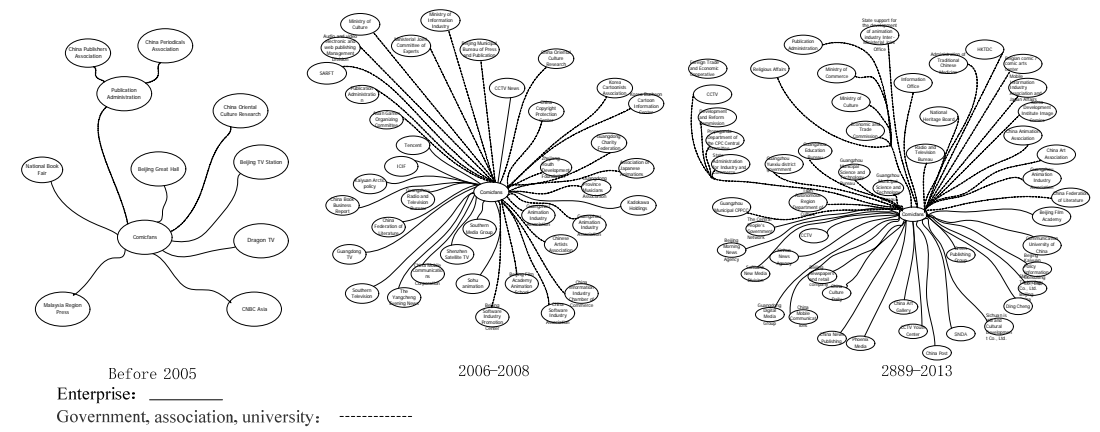

\subsection{Guangzhou Comicfans enterprise network integration and competition analysis}

\subsubsection{Comicfans integration of network characteristics and competitive behavior relationship}

From Comicfans's analysis, we could find that its national market behavior frequency was higher than the regional market behavior frequency, which illustrated that Comicfans was a creative firm with the insistence of carrying out the national market strategy. However, in the problem of the complicacy of competing strategy, Comicfans lacked the advantage of combination. Chart 2 stated that the national complicacy was worser than regional complicacy, and standard deviation of national complicacy was higher than regional complicacy. In addition, Comicfans's national competitive behavior frequency had a significant correlation with the performance, but the complexity of national competitive behavior had no significant correlation with the performance. The frequency and complexity of regional competitive behavior had a significant correlation with the performance.

Chart 2: Comicfans integration of network characteristics and competitive behavior

\begin{tabular}{|c|c|c|c|c|c|c|c|c|}
\hline & $\begin{array}{l}\text { mean } \\
\text { value }\end{array}$ & $\begin{array}{l}\text { Standard } \\
\text { deviation }\end{array}$ & 1 & 2 & 3 & 4 & 5 & 6 \\
\hline $\begin{array}{l}1 \text { National } \\
\text { market } \\
\text { behavior } \\
\text { frequency }\end{array}$ & 4.470588 & 4.665266 & 1 & & & & & \\
\hline $\begin{array}{l}2 \text { Frequency } \\
\text { behavior of the } \\
\text { regional } \\
\text { market }\end{array}$ & 0.411765 & 1.00367 & 0.433 & 1 & & & & \\
\hline $\begin{array}{l}3 \text { National } \\
\text { complexity }\end{array}$ & -12.7011 & 54.19337 & $.776^{* *}$ & 0.347 & 1 & & & \\
\hline $\begin{array}{l}4 \text { Regional } \\
\text { Complexity }\end{array}$ & -10.7734 & 15.39939 & 0.476 & $.634^{* *}$ & $.495 *$ & 1 & & \\
\hline $\begin{array}{l}5 \text { Network } \\
\text { density }\end{array}$ & 9.705882 & 16.22407 & $.499 *$ & 0.416 & 0.393 & $.530 *$ & 1 & \\
\hline $\begin{array}{l}6 \text { Government } \\
\text { relationship }\end{array}$ & 24.89388 & 37.52427 & .601 & $0.479 * *$ & 0.421 & .491 & $.963 *$ & 1 \\
\hline $\begin{array}{l}7 \text { Business } \\
\text { Performance }\end{array}$ & - & - & $.329 * *$ & $.402 *$ & .219 & .104 & $.497^{*}$ & .377 \\
\hline
\end{tabular}

On one hand, Comicfans's integrated networks remained the high diversity and also keepped and maintained various external connection basically each year. In the meantime, there was a prominent positive correlation between the density of integrated network and firm's performance. Chart 3 stated that in the process of establishing integration network over the past 10 years, Comicfans choosed the strategy for the national market and the combination of channel resources. This was because the channel resource was crucial for the convergence of animation resources. With a series of external integration Comicfans integrate the diversified and cross-platform animation release channel platform. However, Comicfans integrated network had no significant correlation with the national association of market competition. On the other hand, Comicfans did not necessarily play a leading role in the integrated network, and were often as follow a role hampered by government departments. In the ecological network, it was difficult that the effect of simple correlation density 
and Comicfans national market behavior frequency built competitive advantage and barriers by the complexity of the competition strategy in the national market channels. Therefore, competitive advantage of Comicfans was not stable and was not by their own decision.

Figure 2: Comicfans competition and integration of network density contrast

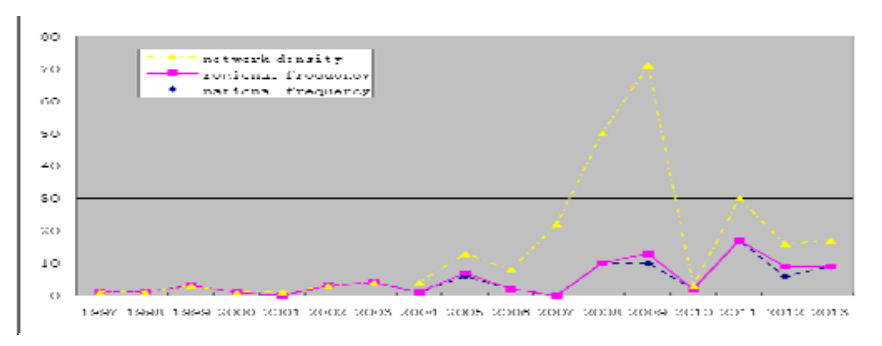

\subsubsection{In which the role of government relationship}

Due to the special characteristics of the institutional environment, animation firms need to strengthen relationship between the various government departments to improve their competitive advantage. Recalling Comicfans news reports each year and memorabilia found, Comicfans adapted to the current industry environment through the integration of government resources and firm resource. But the role of government relationship was very limited. Government relationship had a significant correlation with the frequency of regional competition and integration of network density, but did not correlate with the frequency and complexity of national competitive behavior and the complexity of regional competitive behavior, even did not correlate with performance from chart2.

There were two possibilities: 1) Currently, Comicfans integrated network was not entirely its competitive and development for the purpose, and some integration was forced to adapt to the current system environment, so this external integration was difficult to be reflected in the competitive behavior of firm marketability in the past; 2) Comicfans had not build an effective management mode that current integration network system of the firm.

\section{4 conclusion and discussion}

1.External integration presented a clear creative networking features. While its integrated network was not a whole network, but had a plurality of sub-networks over a network, one of the major sub-networks included: government-linked resources and social networks, firm networks and related industries professional animation innovation network.

2.External integration network of the creative firms had some evolutionary paths. As long as the goal was to integrate more external objects, firms must identify a path "who was integrated first, and who was integrated later", because different types of creative firms need to choose the paths according to their advantages of resources and abilities.

3.Firm integration behavior and competitive behavior need to be coordinated to create competitive advantage in the integration network of creative enterprises. We believed that external integration network of the creative firms more need the flexibility to adapt to the environment than the traditional industry firms. Because the purpose of competition was to get more scarce resources, the competitive behavior of the creative firms was not always the place where the competition was concentrated, but more likely to integrate the larger network density and more important part of association.

4.Government relationship played an important part of creative firms external integration mode. Creative firms should establish the relationship among different levels of government, but couldn't rely on the governments.

\section{Acknowledgement}

This paper supported by the Youth Project of Guangzhou Academy of Social Science 2016, and the "Guangzhou Focus Research Base of Humanities and Social Science: The Word Famous Cultural City and Cultural Industry Research”.” 


\section{Literature References}

[1]Alshamali, M., M. Alfadly and N.I. Abumustafa, Financial and social barriers to bank merger and acquisition[J]. Journal of Derivatives \& Hedge Fundes, 2008. 14(3/4): 160-197.

[2]Hitt, M.A., Ahlstrom, D., Dacin, M.T., Levitas, E., \& Svobodina, L. The institutional effects on strategic alliance partner selection in transition economies: China vs Russia[J]. Organization Science. 2004, 15(2): 173-185.

[3]Yip G S, Loewe P M, Yoshino M Y. How to Take Your Company to the Global Market[J]. Columbia Journal of World Business, 1988, 23(4): 37-48.

[4]Yip G S. Global strategy... in a world of nations[J]. Sloan Management Review, 1989, 31(1): 29-41.

[5] Ali HajShirmohammadi and William C. Wedley. Maintenance management -an AHP application for centralization/decentralization[J]. Journal of Quality in Maintenance Engineering. 2004, 10(1): $16-25$

[6] Hennart, J. F. The transaction costs theory of joint ventures: an empirical study of japanese subsidiaries in the united states[J]. Management Science, 1991, 37(4), 483-497.

[7] Bartlett, C. A.\&Ghoshal, S. Managing across borders: The transnational solution Boston[M]. MA: Harvard Business School Press, 1989

[8] Capron L, Guillen M. National corporate governance institutions and post-acquisition target reorganization[J]. Strategic Management Journal, 2009, 30(8): 803-833.

[9] Bartlett, C. A.\&Ghoshal, S. Managing across borders: The transnational solution Boston[M]. MA: Harvard Business School Press, 1989

[10] Ferrier W J, Grimm C M. The Role of Competitive Action in Market Share Erosion and Industry Dethronement: A Study of Industry Leaders and Challengers[J]. Academy of Management Journal, 1999, 42(4): 372-388.

[11] Gnyawali D, He J, Madhavan R. Impact of Co-Opetition on Firm Competitive Behavior: An Empirical Examination[J]. Journal of Management, 2006, 32(4): 507-530. 